\title{
Deletion of AIF1 but not of YCA1/MCA1 protects Saccharomyces cerevisiae and Candida albicans cells from caspofungin-induced programmed cell death
}

\author{
Christopher Chin ${ }^{1,2, \#, ~ F a i t h ~ D o n a g h e y ~}{ }^{1, \#, ~ K a t h e r i n e ~ H e l m i n g ~}{ }^{1,3, \#}$, Morgan McCarthy ${ }^{1, \#}$, Stephen Rogers ${ }^{1}$, and \\ Nicanor Austriaco ${ }^{1, *}$ \\ 1 Department of Biology, Providence College, Providence, RI 02918, U.S.A. \\ ${ }^{2}$ Current address: University of Massachusetts School of Medicine, 55 Lake Ave. N., Worcester, MA 01655, U.S.A. \\ ${ }^{3}$ Current address: Dana-Farber Cancer Institute, 44 Binney St., Boston, MA 02115, U.S.A. \\ \# These authors contributed equally to this work, and are listed in alphabetical order. \\ * Corresponding Author: Rev. Nicanor Pier Giorgio Austriaco, O.P., Ph.D., Department of Biology, Providence College, Providence, RI \\ 02918, USA; Tel: 401-865-1823; Fax: 401-865-2959; E-mail: naustria@providence.edu
}

\begin{abstract}
Caspofungin was the first member of a new class of antifungals called echinocandins to be approved by a drug regulatory authority. Like the other echinocandins, caspofungin blocks the synthesis of $\beta(1,3)$-D-glucan of the fungal cell wall by inhibiting the enzyme, $\beta(1,3)$-D-glucan synthase. Loss of $\beta(1,3)$-D-glucan leads to osmotic instability and cell death. However, the precise mechanism of cell death associated with the cytotoxicity of caspofungin was unclear. We now provide evidence that Saccharomyces cerevisiae cells cultured in media containing caspofungin manifest the classical hallmarks of programmed cell death (PCD) in yeast, including the generation of reactive oxygen species (ROS), the fragmentation of mitochondria, and the production of DNA strand breaks. Our data also suggests that deleting AIF1 but not YCA1/MCA1 protects $S$. cerevisiae and Candida albicans from caspofungininduced cell death. This is not only the first time that AIF1 has been specifically tied to cell death in Candida but also the first time that caspofungin resistance has been linked to the cell death machinery in yeast.
\end{abstract}

\author{
doi: $10.15698 /$ mic2014.01.119 \\ Received originally: 22.10.2013; in \\ revised form: 31.10 .2013 , \\ Accepted 04.11.2013, \\ Published 15.01.2014.
}

Keywords: caspofungin, AIF1, MCA1/YCA1, programmed cell death, Saccharomyces cerevisiae, Candida albicans.

\section{INTRODUCTION}

Defined as any cell death that results from the activation of a genetic program, programmed cell death (PCD) has been classified by the Nomenclature Committee on Cell Death (NCCD) into twelve different functional categories based on measurable biochemical features [1]. In recent years, numerous laboratories have shown that a wide range of antifungal drugs leads to PCD in yeast that is reminiscent of apoptosis in mammalian cells [2]. This cell death is accompanied by several distinctive phenotypical markers, including the generation of reactive oxygen species (ROS), the fragmentation of mitochondria, and the dissipation of the mitochondrial membrane potential [3-5]. It also involves intrinsic pathways of cell death defined by several genes, including AIF1, BIR1, BXI1, NMA111, and YCA1, which have homologs in the metazoa [6-11].

Caspofungin was the first member of the class of antifungals called the echinocandins to be approved by a drug regulatory authority $[12,13]$. Like the other echinocandins, caspofungin blocks the synthesis of $\beta(1,3)$-D-glucan of the fungal cell wall by inhibiting the enzyme, $\beta(1,3)$-D-glucan synthase [14]. However, the precise mechanism of cell death associated with the cytotoxicity of caspofungin was unclear.

In this report, we provide evidence that Saccharomyces cerevisiae cells cultured in media containing caspofungin manifest the classical hallmarks of PCD in yeast, including the generation of reactive oxygen species (ROS), the fragmentation of mitochondria, and the activation of caspaselike activity. Moreover, our data also suggests that this cell death scenario requires the pro-apoptotic gene, AIF1, but not the metacaspase, YCA1, in both S. cerevisiae and Candida albicans. Our findings reveal an additional dimension of caspofungin's mechanism of action as a general antifungal agent that points to a possible novel pathway to drug resistance. 


\section{RESULTS AND DISCUSSION}

To determine if caspofungin triggers PCD in budding yeast, we cultured W303-1A cells in YPD containing $0.02 \mu \mathrm{g} / \mathrm{ml}$ caspofungin for three hours, a drug concentration below the MIC of $0.04 \mu \mathrm{g} / \mathrm{ml}$ for this strain (data not shown). With this protocol, propidium iodide staining $(50 \mu \mathrm{g} / \mathrm{ml})$ revealed that just over half of the cells $(58 \pm 10 \% ; p<0.005)$ were viable as compared to cells grown in the absence of drug $(99 \pm 0.1 \%)$. The cells were also treated with $2.5 \mu \mathrm{M}$ CellROX Green (Molecular Probes, Inc.) and imaged with a Zeiss

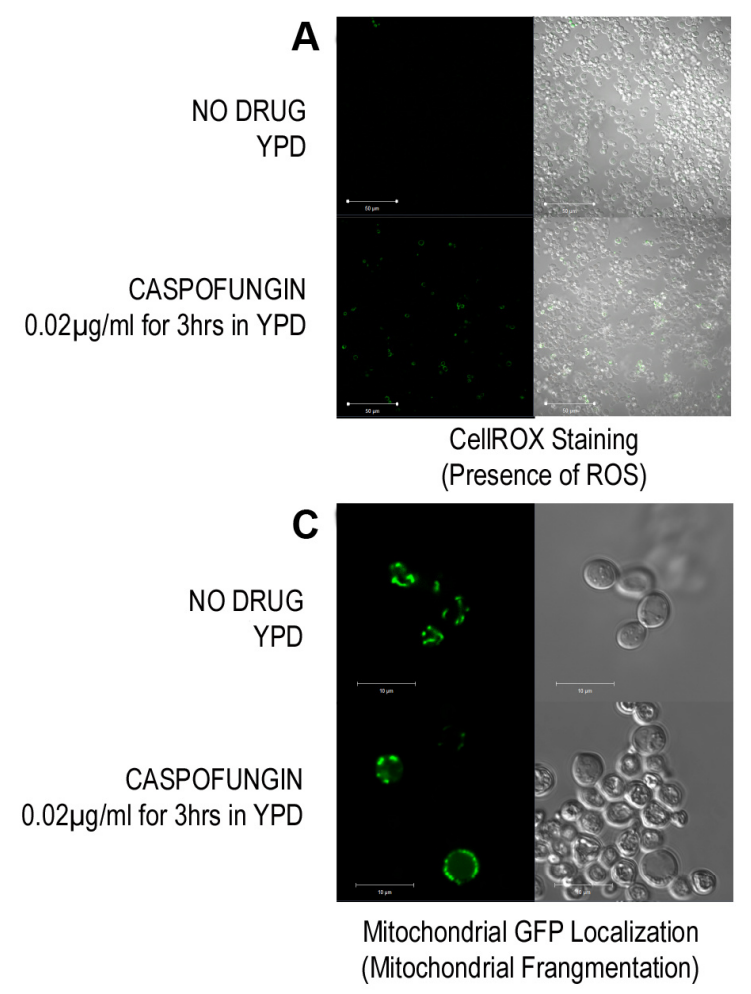

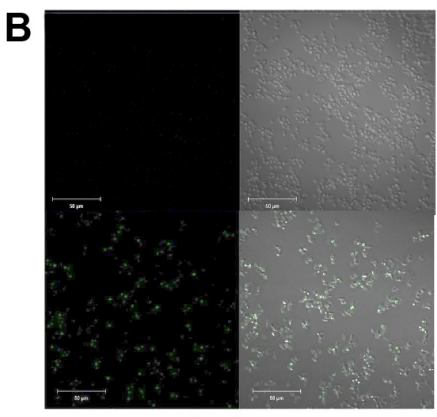

FLICA Assay

(Presence of Caspase Activity)

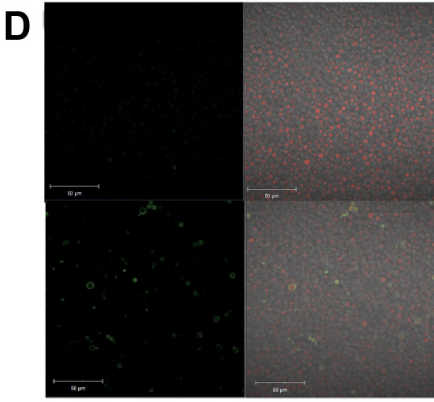

JC-1 Staining

(Mitochondrial Membrane Potential)
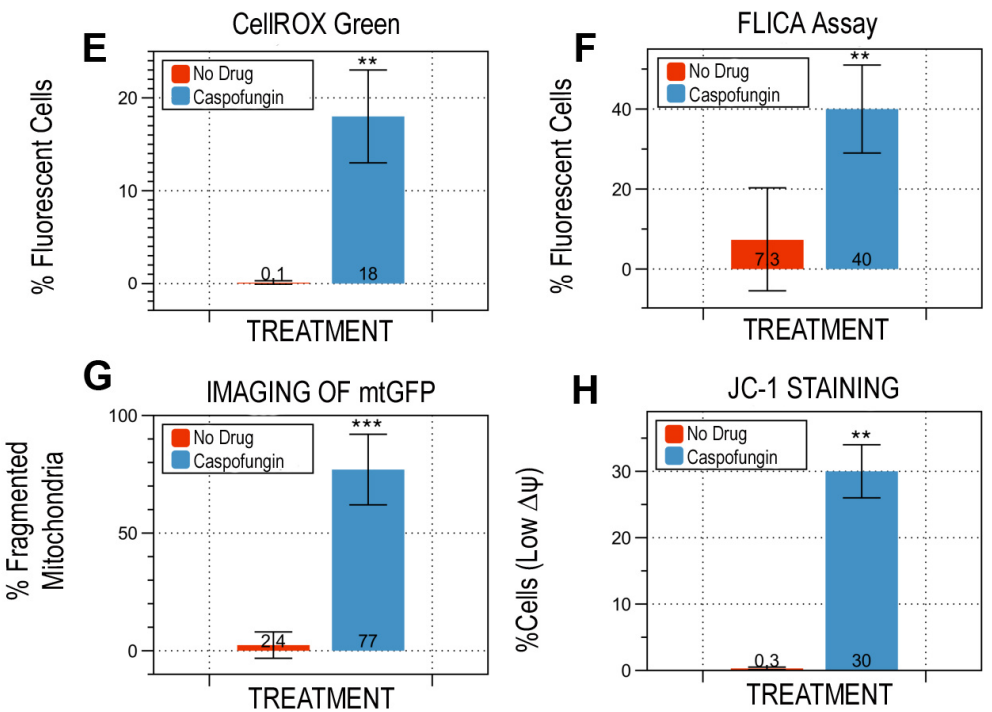

FIGURE 1: Saccharomyces cerevisiae cells cultured in caspofungin manifest numerous phenotypic markers associated with yeast programmed cell death. Exponentially-growing wildtype cells from the W303-1A strain background were cultured in YPD containing $0.02 \mu \mathrm{g} / \mathrm{ml}$ caspofungin for three hours. The cells were stained with $2.5 \mu \mathrm{M}$ CellROX Green to detect ROS (A, E); with a FLICA kit to detect activated caspase activity (B, F); and with the mitochondrial vital dye, JC-1, to assess their mitochondrial membrane potential (D, H). To visualize the structure of their mitochondria, the cells were transformed with a p416 GPD-mtGFP plasmid constitutively expressing a mitochondria-localized GFP marker and their mitochondria were visualized after they had been treated with caspofungin as described above (C, G). Representative images are shown (A-D). Statistical significance for the graphs (E-H) was determined with the unpaired Student's ttest $\left({ }^{* *}: p<0.05 ;{ }^{* *}: p<0.005\right)$, and a minimum of 500 cells was counted for each assay. 
LSM700 confocal microscope. We discovered that including caspofungin in the culture media generates significantly more fluorescent cells $(18 \pm 5 \%$; $p<0.05$; Figure $1 A, E)$ as compared to controls $(0.1 \pm 0.2 \%)$ suggesting that the drug induces the production of ROS, a characteristic hallmark of apoptotic cell death in yeast $[3,15]$.

Next, we used a FLICA apoptosis detection kit (ImmunoChemistry Technologies, LLC) according to the manufacturer's specifications to determine if the caspofungin treatment described above also induced caspase activity in W303-1A cells. Numerous studies have associated caspase activation with apoptotic cell death, not only in yeast, but also in mammalian cells [16-18]. We discovered that drug treatment leads to significantly more cells with activated caspase-like activity $(40 \pm 11 \%$; $<<0.05$; Figure $1 B, F)$ as compared to no-drug controls $(7.3 \pm 13 \%)$.

Third, we imaged the same yeast cells, this time transformed with the p416 GPD-mtGFP plasmid constitutively expressing a mitochondria-localized GFP marker to visualize the structure of their mitochondria [19], after they had been treated with caspofungin as described above. Several reports have shown that apoptosis in Saccharomyces cerevisiae is accompanied by the fragmentation of mitochondria $[4,20]$. Our experiments revealed that the majority of mitochondria of the caspofungin-treated cells had lost their tubular architecture after three hours $(77 \pm 15 \%$; $\mathrm{p}<0.005$; Figure $1 \mathrm{C}, \mathrm{G})$. In contrast, only a few cells cultured in media without the drug $(2.4 \pm 5.6 \%)$ displayed the punctate mitochondrial-staining pattern associated with fragmented mitochondria.

Fourth, to determine the functional state of the mitochondria in cells treated with caspofungin as described above, we incubated the cells with the mitochondrial vital dye, JC-1 (5mM; Molecular Probes, Inc.) for $15 \mathrm{~min}$ at $30^{\circ} \mathrm{C}$ to assess their mitochondrial membrane potential $\left(\Delta \psi_{\mathrm{m}}\right)$. In healthy cells with high $\Delta \psi_{\mathrm{m}}, \mathrm{JC}-1$ forms aggregates that exhibit intense red fluorescence, while in apoptotic cells with low $\Delta \psi_{m}$, the dye remains in the monomeric form, which has green fluorescence [21-23]. Our experiments revealed that caspofungin-treated W303-1A cells had significantly more unhealthy cells with low $\Delta \psi_{\mathrm{m}}(30 \pm 4 \%$; $p<0.05$; Figure $1 \mathrm{D}, \mathrm{H})$ than untreated controls $(0.3 \pm 0.2 \%)$.

In toto, all of our data suggests that caspofungin induces PCD in $S$. cerevisiae cells. Notably, while our studies were in progress, a paper was published that reported that caspofungin induces PCD in the yeast, Candida albicans, accompanied with phenotypic markers characteristic of apoptosis and necrosis, including some of the markers described above [24]. We have repeated and confirmed these results suggesting that caspofungin kills with a similar

A

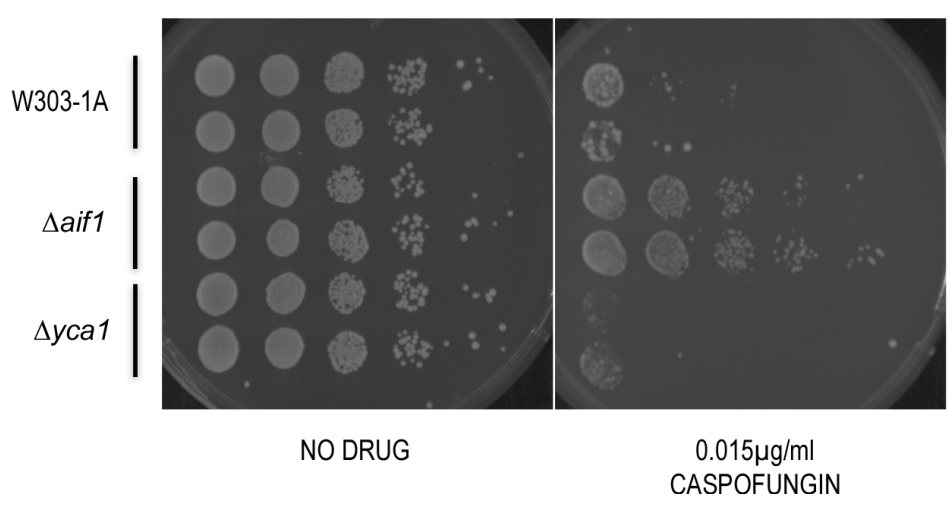

B

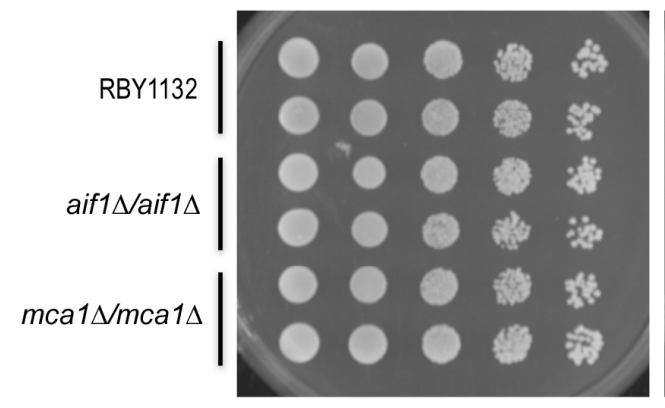

NO DRUG

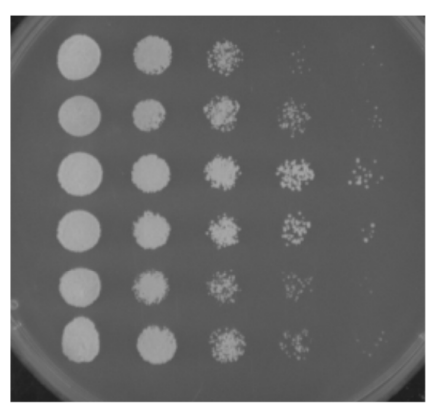

$0.2 \mu \mathrm{g} / \mathrm{ml}$ CASPOFUNGIN

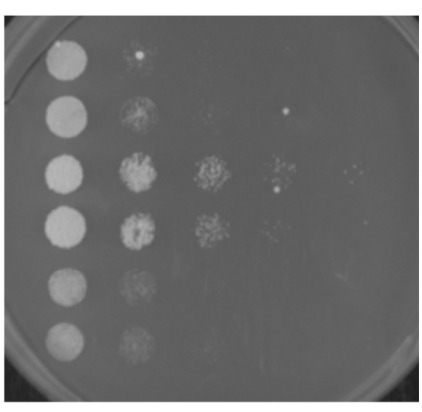

$0.4 \mu \mathrm{g} / \mathrm{ml}$ CASPOFUNGIN

FIGURE 2: Deletion of AIF1 but not YCA1/MCA1 protects Saccharomyces cerevisiae and Candida albicans cells from caspofungininduced programmed cell death. (A) A series of ten-fold dilutions of two cultures each of wildtype, $\Delta a$ if, and $\triangle y c a 1$ W303-1A Saccharomyces cells were plated on YPD plates and YPD plates with $0.015 \mu \mathrm{g} / \mathrm{ml}$ caspofungin for two days. (B) A series of ten-fold dilutions of two independent cultures each of wildtype, aif $\Delta /$ aif $\Delta$ and mca1 $\Delta$ /mca1 $\Delta$ RBY1132 Candida cells were plated on YPD plates and YPD plates with the indicated concentrations of caspofungin for two days. Representative images are shown. 
mechanism of action in both Saccharomyces cerevisiae and Candida albicans (data not shown).

Finally, ROS-mediated PCD in yeast is often distinguished into two different types depending upon their mechanism of killing, either caspase-dependent or caspase-independent yeast apoptosis [18, 25, 26]. Caspasedependent cell death can be bypassed, at least in part, by the deletion of the yeast metacaspase, YCA1/MCA1 [6, 27, 29]. In contrast, caspase-independent cell death cannot be suppressed by a YCA1/MCA1 deletion [29]. Importantly, the yeast homolog of the mammalian apoptosis-inducing factor, called AIF1 in both Saccharomyces cerevisiae and Candida alibcans, has often been linked to caspaseindependent cell death $[7,25]$.

While the recent paper showed that caspofungin induces PCD in Candida, it did not determine the mechanism of killing for the drug [24]. Indeed, the authors proposed that future studies should determine if either the caspasedependent or the independent pathway is also involved in regulating yeast apoptosis upon exposure of caspofungin. To see if caspofungin induces either caspase-dependent or caspase-independent cell death, we spotted a series of ten-fold dilutions of two cultures each of wildtype, $\Delta$ aif1, and $\triangle y c a 1$ W303-1A cells on YPD plates and YPD plates with caspofungin. After two days, we discovered that the viability of cells lacking the metacaspase was indistinguishable from that of wildtype cells (Figure $2 \mathrm{~A}$ ). This suggests that the caspase-like activity that we observed with our FLICA assay described above is associated with caspases and/or proteases other than Yca1p [18]. However, Laif1 cells were relatively more resistant to caspofungin killing suggesting that this anti-fungal agent triggers AIF1dependent PCD in Saccharomyces cerevisiae (Figure $2 \mathrm{~A}$ ). We repeated these experiments with wildtype, aif1 $1 /$ aif $1 \Delta$, and mca $1 \Delta /$ mca $1 \Delta$ mutants of Candida albicans, generously provided by Richard Bennett (Brown University). MCA1 is the Candida albicans homolog of the Saccharomyces cerevisiae metacaspase gene, YCA1 [16], while AIF1 (orf19.3362) is the single homolog of the Saccharomyces AIF1 gene $[7,25]$. The assay was repeated with two independent isolates for each Candida null mutant to ensure that the observed phenotype is due to the knockout of the ORF and not to some spurious mutation. Once again, after two days incubation, we discovered that aif1 /aif1 $\Delta$ cells were more resistant to caspofungin than either wildtype or $m c a 1 \Delta /$ mca1 $\Delta$ cells (Figure $2 \mathrm{~B}$ ).

In conclusion, our study suggests that caspofungin leads to caspase-independent cell death requiring AIF1 in both Saccharomyces cerevisiae and Candida albicans. Of significance, though caspase-independent cell death has been observed in Candida before [29], this is the first time that AIF1 has been implicated in this process for this pathogenic yeast. In sum, our findings reveal an additional dimension of this echinocandin's mechanism of action as an anti-fungal agent. They also point to a novel scenario for the acquisition of caspofungin resistance since this is the first time that drug resistance in Candida has been linked to a gene involved in cell death.

\section{MATERIALS AND METHODS}

Yeast Strains and Growth Conditions

All experiments were done with isogenic Saccharomyces cerevisiae strains in the W303-1A background (MATa ade2, his3, leu2, trp1, ura3, ssd1-d2). The $\Delta y c a 1$ mutant (SKY2880) was previously described [30]. The $\Delta a i f 1$ mutant was created by disrupting the ORF with the kanR marker using a PCR-based knock-out strategy [31] and verified both by PCR and by phenotypic analysis. Experiments with Candida albicans were done with wildtype, aif $1 \Delta / a i f 1 \Delta$, and $m c a 1 \Delta /$ mca $1 \Delta$ mutants of Candida albicans, generously provided by Richard Bennett (Brown University). Mutants were created in the wildtype RBY1132 strain background (MTL a/a, leu2/leu2 his1/his1 arg4/arg4) by disrupting the ORF with a disruption cassette generated by fusion PCR and verified as previously described [32]. For all the experiments described in this paper, cells were cultured using standard protocols [33]. Caspofungin (Cancidas) was generously provided by Merck (Rahway, NJ) and by Timothy Flanigan (Rhode Island Hospital/Warren Alpert School of Medicine at Brown University). Unless noted otherwise, all other drugs and reagents were purchased from SIGMA-Aldrich.

\section{Caspofungin Activity Assay}

Wildtype budding yeast cells in the W303-1A background were cultured in YPD overnight. In the morning, they were reinoculated in fresh media and allowed to grow for several hours until they reached the exponential phase $\left(\mathrm{OD}_{600} 0.2-0.4\right)$. They were then resuspended at the same cell density in fresh media or in fresh media containing $0.02 \mu \mathrm{g} / \mathrm{ml}$ caspofungin for three hours, a drug concentration below the MIC of $0.04 \mu \mathrm{g} / \mathrm{ml}$ for this strain (data not shown). Next, the cells were washed and resuspended in a solution of YPD and $50 \mu \mathrm{g} / \mathrm{ml}$ propidium iodide. Propidium iodide is a membrane impermeable fluorescent molecule that is excluded from viable cells. Fluorescent cells were counted with either a Zeiss Axiophot Fluorescence Microscope or a Zeiss LSM 700 Laser Confocal Microscope fitted with Filter Cube 43 Cy3/Rhod/RFP (EX BP 545/25, BS FT 565, EM BP 606/70). Measurements were repeated with at least three independent cell cultures.

\section{Apoptosis Assays}

Wildtype budding yeast cells in the W303-1A background were cultured in YPD overnight. In the morning, they were reinoculated in fresh media and allowed to grow for several hours until they reached the exponential phase $\left(O_{600} 0.2-0.4\right)$. They were then resuspended at the same cell density in fresh media or in fresh media containing $0.02 \mu \mathrm{g} / \mathrm{ml}$ caspofungin for three hours. To detect the presence of reactive oxygen species (ROS), they were stained with $2.5 \mu \mathrm{M}$ CellROX Green (Molecular Probes, Inc.) for $10 \mathrm{~min}$ at room temperature. This cellpermeable dye exhibits bright fluorescence upon oxidation by ROS, which was visualized with a Zeiss LSM700 confocal microscope fitted with Filter Cube 38 GFP (EX BP 470/40, BS FT 495, EM BP 525/50). Next, to determine the presence of activated caspase-like activity, they were stained with a FLICA apoptosis detection kit (ImmunoChemistry Technologies, LLC) according to the manufacturer's specifications, and imaged with a Zeiss LSM700 confocal microscope fitted with Filter Cube 38 GFP. Third, to determine the functional state of the mitochondria in cells treated with caspofungin as described above, they were incubated with the mitochondrial vital dye, JC-1 (5mM; Molecular Probes, Inc.) for $15 \mathrm{~min}$ at $30^{\circ} \mathrm{C}$ to assess 
their mitochondrial membrane potential $\left(\Delta \psi_{m}\right)$. In healthy cells with high $\Delta \psi_{\mathrm{m}}, \mathrm{JC}-1$ forms aggregates that exhibit intense red fluorescence, while in apoptotic cells with low $\Delta \psi_{\mathrm{m}}$, the dye remains in the monomeric form, which has green fluorescence [21-23]. Both were imaged with the Zeiss LSM700 fitted either with Filter Cube 43 Cy3/Rhod/RFP or with Filter Cube 38 GFP. Finally, to detect the fragmentation of mitochondria, the cells were transformed with a p416 GPD-mtGFP plasmid constitutively expressing a mitochondria-localized GFP marker [19], treated with caspofungin as described above, and imaged with a Zeiss LSM 700 Laser Confocal Microscope fitted with Filter Cube 38 GFP. For all the apoptosis assays, the experiment was repeated with at least three independent cultures. Representative images are shown with consistent parameters applied to comparable panels in each figure. Statistical significance was determined with the unpaired Student's ttest, and a minimum of 500 cells was counted for each assay.

\section{Spot Assays}

Wildtype and mutant cells of the indicated genotypes were grown overnight in YPD at $30^{\circ} \mathrm{C}$ (Saccharomyces) or at $37^{\circ} \mathrm{C}$ (Candida) respectively. For each yeast strain, a series of 10fold dilutions was then prepared in water with cells in the exponential phase $\left(\mathrm{OD}_{600} 0.2-0.4\right)$ over a range of concentrations from $10^{-1}$ to $10^{-5}$ relative to the initial culture. Spots of 5 $\mu \mathrm{l}$ from each dilution series were then plated on the indicated media and cultured at $30^{\circ} \mathrm{C}$ (Saccharomyces) or at $37^{\circ} \mathrm{C}$ (Candida) for 2 days. Plates supplemented with caspofungin were poured and used on the same day. All spot assays were repeated at least three times and a representative experiment is shown.

\section{ACKNOWLEDGMENTS}

We thank Richard Bennett (Brown University) for the Candida strains, Stephen Kron (University of Chicago) for

\section{REFERENCES}

1. Galluzzi L, Vitale I, Abrams JM, Alnemri ES, Baehrecke $\mathrm{EH}_{\text {, }}$ Blagosklonny MV, Dawson TM, Dawson VL, El-Deiry WS, Fulda $S$, Gottlieb E, Green DR, Hengartner MO, Kepp O, Knight RA, Kumar S, Lipton SA, Lu X, Madeo F, Malorni W, Mehlen P, Nunez G, Peter ME, Piacentini M, Rubinsztein DC, Shi Y, Simon HU, Vandenabeele P, White E, Yuan J, et al. (2012). Molecular definitions of cell death subroutines: recommendations of the Nomenclature Committee on Cell Death 2012. Cell Death Differ 19(1): 107-20.

2. Almeida B, Silva A, Mesquita A, Sampaio-Marques B, Rodrigues F, Ludovico $P$ (2008). Drug-induced apoptosis in yeast. Biochim Biophys Acta 1783(7): 1436-48.

3. Madeo F, Frohlich E, Ligr M, Grey M, Sigrist SJ, Wolf DH, Frohlich KU (1999). Oxygen stress: a regulator of apoptosis in yeast. J Cell Biol 145(4): 757-67.

4. Fannjiang Y, Cheng WC, Lee SJ, Qi B, Pevsner J, McCaffery JM, Hill RB, Basanez G, Hardwick JM (2004). Mitochondrial fission proteins regulate programmed cell death in yeast. Genes Dev 18(22): 2785-97.

5. Madeo F, Frohlich E, Frohlich KU (1997). A yeast mutant showing diagnostic markers of early and late apoptosis. J Cell Biol 139(3): 72934.

6. Madeo F, Herker E, Maldener C, Wissing S, Lachelt S, Herlan M, Fehr M, Lauber K, Sigrist SJ, Wesselborg S, Frohlich KU (2002). A caspaserelated protease regulates apoptosis in yeast. Mol Cell 9(4): 911-7.
SKY2880, May Godoy and her colleagues (Merck Research Laboratories, Rahway, NJ) for providing us with caspofungin, and for helpful comments on an earlier version of this paper, Timothy Flanigan (Rhode Island Hospital/Warren Alpert School of Medicine at Brown University) for additional caspofungin, John Yang (Providence College) for technical support, and Antoninus Niemiec, O.P., for help with preparation of the figures. Our laboratory is supported by the following grants awarded to N. Austriaco: NIGMS R15 GM094712, NSF MRI-R2 0959354, and NIH/Rhode Island INBRE Program Grant 8 P20 GM103430-12 for undergraduate student training. Non nisi te, Domine.

\section{CONFLICT OF INTEREST}

The authors declare no conflict of interest.

\section{COPYRIGHT}

(C) Chin et al. This is an open-access article released under the terms of the Creative Commons AttributionNonCommercial-NonDerivative 3.0 license, which allows readers to download the article and share it with others, provided that the original authors and source are acknowledged. The article cannot be changed in any way or used commercially.

Please cite this article as: Christopher Chin, Faith Donaghey, Katherine Helming, Morgan McCarthy, Stephen Rogers, and Nicanor Austriaco (2014). Deletion of AIF1 but not of YCA1/MCA1 protects Saccharomyces cerevisiae and Candida albicans cells from caspofungin-induced programmed cell death. Microbial Cell 1(2): 58-63. doi: 10.15698/mic2014.01.119

7. Wissing S, Ludovico P, Herker E, Buttner S, Engelhardt SM, Decker T, Link A, Proksch A, Rodrigues F, Corte-Real M, Frohlich KU, Manns J, Cande C, Sigrist SJ, Kroemer G, Madeo F (2004). An AIF orthologue regulates apoptosis in yeast. J Cell Biol 166(7): 969-74.

8. Sharon A, Finkelstein A, Shlezinger N, Hatam I (2009). Fungal apoptosis: function, genes and gene function. FEMS Microbiol Rev 33(5): 833-54

9. Walter D, Wissing S, Madeo F, Fahrenkrog B (2006). The inhibitorof-apoptosis protein Bir1p protects against apoptosis in $S$. cerevisiae and is a substrate for the yeast homologue of Omi/HtrA2. J Cell Sci 119(Pt 9): 1843-51.

10. Fahrenkrog B, Sauder U, Aebi U (2004). The S. cerevisiae HtrA-like protein Nma111p is a nuclear serine protease that mediates yeast apoptosis. J Cell Sci 117(Pt 1): 115-26.

11. Cebulski J, Malouin J, Pinches N, Cascio V, Austriaco N (2011). Yeast Bax inhibitor, Bxi1p, is an ER-localized protein that links the unfolded protein response and programmed cell death in Saccharomyces cerevisiae. PLoS One 6(6): e20882.

12. Letscher-Bru V, Herbrecht $R$ (2003). Caspofungin: the first representative of a new antifungal class. J Antimicrob Chemother 51(3): 513-21. 
13. Onishi J, Meinz M, Thompson J, Curotto J, Dreikorn S, Rosenbach M, Douglas C, Abruzzo G, Flattery A, Kong L, Cabello A, Vicente F, Pelaez F, Diez MT, Martin I, Bills G, Giacobbe R, Dombrowski A, Schwartz R, Morris S, Harris G, Tsipouras A, Wilson K, Kurtz MB (2000). Discovery of novel antifungal (1,3)-beta-D-glucan synthase inhibitors. Antimicrob Agents Chemother 44(2): 368-77.

14. Douglas CM, D'Ippolito JA, Shei GJ, Meinz M, Onishi J, Marrinan JA Li W, Abruzzo GK, Flattery A, Bartizal K, Mitchell A, Kurtz MB (1997). Identification of the FKS1 gene of Candida albicans as the essential target of 1,3-beta-D-glucan synthase inhibitors. Antimicrob Agents Chemother 41(11): 2471-9.

15. Perrone GG, Tan SX, Dawes IW (2008). Reactive oxygen species and yeast apoptosis. Biochim Biophys Acta 1783(7): 1354-68.

16. Shirtliff ME, Krom BP, Meijering RA, Peters BM, Zhu J, Scheper MA Harris ML, Jabra-Rizk MA (2009). Farnesol-induced apoptosis in Candida albicans. Antimicrob Agents Chemother 53(6): 2392-401.

17. Zhu J, Krom BP, Sanglard D, Intapa C, Dawson CC, Peters BM, Shirtliff ME, Jabra-Rizk MA (2011). Farnesol-induced apoptosis in Candida albicans is mediated by Cdr1-p extrusion and depletion of intracellular glutathione. PLoS One 6(12): e28830.

18. Wilkinson D, Ramsdale M (2011). Proteases and caspase-like activity in the yeast Saccharomyces cerevisiae. Biochemical Society transactions 39(5): 1502-8.

19. Okamoto K, Kondo-Okamoto N, Ohsumi Y (2009). Mitochondriaanchored receptor Atg32 mediates degradation of mitochondria via selective autophagy. Developmental cell 17(1): 87-97.

20. Kitagaki H, Araki Y, Funato K, Shimoi H (2007). Ethanol-induced death in yeast exhibits features of apoptosis mediated by mitochondrial fission pathway. FEBS Lett 581(16): 2935-42.

21. Cossarizza A, Salvioli S (2001). Flow cytometric analysis of mitochondrial membrane potential using JC-1. Current protocols in cytometry / editorial board, J Paul Robinson, managing editor [et al] Chapter 9(Unit 9 14).

22. Salvioli S, Ardizzoni A, Franceschi C, Cossarizza A (1997). JC-1, but not DiOC6(3) or rhodamine 123 , is a reliable fluorescent probe to assess delta psi changes in intact cells: implications for studies on mitochondrial functionality during apoptosis. FEBS Lett 411(1): 77-82.
23. Cossarizza A, Salvioli S (2001). Analysis of mitochondria during cell death. Methods in cell biology 63(467-86).

24. Hao B, Cheng S, Clancy CJ, Nguyen MH (2013). Caspofungin kills Candida albicans by causing both cellular apoptosis and necrosis. Antimicrob Agents Chemother 57(1): 326-32.

25. Madeo F, Carmona-Gutierrez D, Ring J, Buttner S, Eisenberg T, Kroemer G (2009). Caspase-dependent and caspase-independent cell death pathways in yeast. Biochem Biophys Res Commun 382(2): $227-$ 31.

26. Carmona-Gutierrez D, Eisenberg T, Buttner S, Meisinger C, Kroemer G, Madeo F (2010). Apoptosis in yeast: triggers, pathways, subroutines. Cell Death Differ 17(5): 763-73.

27. Mazzoni C, Falcone C (2008). Caspase-dependent apoptosis in yeast. Biochim Biophys Acta 1783(7): 1320-7.

28. Fu Z, Lu H, Zhu Z, Yan L, Jiang Y, Cao Y (2011). Combination of baicalein and Amphotericin B accelerates Candida albicans apoptosis. Biological \& pharmaceutical bulletin 34(2): 214-8.

29. Aerts AM, Carmona-Gutierrez D, Lefevre S, Govaert G, Francois IE, Madeo F, Santos R, Cammue BP, Thevissen K (2009). The antifungal plant defensin RsAFP2 from radish induces apoptosis in a metacaspase independent way in Candida albicans. FEBS Lett 583(15): 2513-6.

30. Wysocki R, Kron SJ (2004). Yeast cell death during DNA damage arrest is independent of caspase or reactive oxygen species. J Cell Biol 166(3): 311-6

31. Brachmann CB, Davies A, Cost GJ, Caputo E, Li J, Hieter P, Boeke JD (1998). Designer deletion strains derived from Saccharomyces cerevisiae S288C: a useful set of strains and plasmids for PCRmediated gene disruption and other applications. Yeast 14(2): 115-32.

32. Alby K, Schaefer D, Sherwood RK, Jones SK, Jr., Bennett RJ (2010). Identification of a cell death pathway in Candida albicans during the response to pheromone. Eukaryot Cell 9(11): 1690-701.

33. Amberg DC, Burke D, Strathern J (2005). Methods in Yeast Genetics. Cold Spring Harbor Laboratory Press, Cold Spring Harbor, NY. ISBN 978-087969728-0 